\title{
Considerações sobre a pobreza no Brasil e suas manifestações nas cidades da Amazônia*
}

Ana Cláudia Duarte Cardoso - Professora do Departamento de Arquitetura e Urbanismo da UFPA

Marcília Regina Gama Negrão - Arquiteta Urbanista e mestranda do Programa de PósGraduação em Engenharia Civil da UFPA

\section{Resumo}

Neste artigo, destinado a não especialistas, tecem-se considerações sobre a pobreza, analisando-se suas manifestações nas cidades brasileiras, em particular nas cidades amazônicas, no contexto do liberalismo econômico. Na primeira parte, discutem-se diferentes definições de pobreza, na perspectiva dos países em desenvolvimento. Em seguida, examinam-se as causas estruturais da pobreza e a evolução da compreensão do problema por parte das autoridades no país. Na seqüência, são abordadas as políticas liberais de combate à pobreza recomendadas pelo Banco Mundial e seu impacto sobre as políticas públicas herdadas do Estado de Bem-Estar Social. Seguem-se informações a respeito da abordagem recente do problema pelo governo brasileiro. Por último, são apresentadas as estratégias liberais aplicadas às cidades nas últimas décadas e seus ecos nas cidades amazônicas.

\section{Palavras-chave}

Pobreza, pobreza no Brasil, políticas sociais liberais, cidades amazônicas.

\begin{abstract}
This paper offers information about poverty to non-specialists, contextualising its manifestations on Brazilian and particularly on Amazonian cities, under economic liberalism. Its first section discusses different approaches to poverty, according to developing countries perspectives. Afterwards structural causes to poverty in Brazil and evolution of official understanding to the problem are presented. These are followed by liberal policies to fight poverty recommended by World Bank, and their impacts on public policies inherited from Welfare State, and by the information related to recent approaches of Brazilian government to the problem. At last, liberal strategies applied to cities during the last decades are presented, highlighting their echoes on Amazonian cities.
\end{abstract}

\section{Keywords}

Poverty, poverty in Brazil, socio-liberal policies, Amazonian cities.

$\mathrm{O}$ artigo foi produto do projeto de pesquisa financiado pelo CNPq, intitulado "O espaço informalmente produzido como recurso para superação da pobreza urbana". Mais precisamente foi um capítulo do relatório enviado. 


\section{O QUE É SER POBRE?}

Apesar dos compromissos assumidos em acordos internacionais ao longo dos últimos 60 anos (desde a Declaração Universal dos Direitos Humanos, em 1948, até a Declaração do Milênio, em 2001) no sentido de diminuir a desigualdade entre as pessoas e as populações dos países que os subscreveram, observa-se que as desigualdades têm aumentado, em decorrência de processos políticos e econômicos.

De acordo com os dados apresentados no relatório do Programa das Nações Unidas para o Desenvolvimento (PNUD; IPEA, 1996), 20\% da população mundial (representados principalmente pelos países desenvolvidos) detêm $80 \%$ da renda, enquanto 60\% da população mundial (constituídos integralmente pelos países em desenvolvimento) repartem 5,6\% da renda gerada pelo planeta todo (renda avaliada em dólar). Esses números indicam a gravidade do problema nos países em desenvolvimento e revelam a insuficiência da riqueza produzida nesses países em relação às necessidades de suas populações, assim como a desigualdade na distribuição da riqueza disponível.

Contribuições de várias áreas do conhecimento reconhecem que o aumento da pobreza em países em desenvolvimento não depende apenas de questões econômicas (como a redução das carências materiais), mas também de aspectos sociológicos e políticos, relacionados à concentração de privilégios e ao acesso a direitos sociais (CARDOSO, 2002; DEMO, 1996; SALAMA; VALIER, 1997). Lena Lavinas (2003) elabora um conceito de pobreza com base no conceito de necessidades. Lavinas considera pobre o indivíduo que possui sua humanidade ameaçada, seja pela não satisfação de suas necessidades básicas (fisiológicas e outras), seja pela incapacidade de mobilizar esforços e meios para a satisfação de tais necessidades.

A esse respeito, Lavinas (2003) informa que, na Inglaterra, até a primeira metade do século XIX, as necessidades básicas estavam assentadas em um elenco hierarquizado de prioridades, a começar pelo direito à subsistência. Essa corrente nutricionista associa as necessidades à sobrevivência física, sem levar em consideração elementos de ordem social ou política; o pobre é percebido como o indivíduo que não dispõe de um padrão de subsistência mínimo (TOWNSEND, 1993).

Em um segundo momento, surge uma nova interpretação do que seriam necessidades básicas, e um novo entendimento do que seria pobreza, que não se limita ao nível de renda. Para Townsend (1993), as pessoas são relativamente pobres se não puderem usufruir, plenamente ou suficientemente, de condições de vida (dietas, amenidades, padrões 
e serviços) que lhes permitam atuar, participar e comportar-se tal como seria esperado, na qualidade de membros de uma sociedade.

Outra linha de pensamento, representada por Gough (2000), identifica a saúde e a autonomia como fatores imprescindíveis para a condução de uma vida socialmente ativa e orientada por metas e objetivos que dependam de decisão. Seguindo outra orientação, Sen (1992 apud LAVINAS, 2003) advoga que tão importante quanto ter suas necessidades básicas atendidas, seria dispor de condições - meios para funcionar (functionnings) e um conjunto de habilidades (capability set) - que permitam obter a satisfação de tais necessidades, contestando assim o conceito de pobreza baseado na insuficiência de renda. Lavinas (2003) destaca que Sen não se atém ao orçamento monetário disponível, mas considera o conjunto de habilidades e capacidades ao alcance de cada indivíduo, que permite que cada um escolha livremente o modo de vida de sua preferência.

As definições de pobreza construídas com base em indicadores tipicamente econômicos (renda, ou outros indicadores padronizados para tal fim) servem para que agências internacionais e governos nacionais comparem diferentes realidades e momentos históricos, mas infelizmente são utilizadas para orientar políticas públicas mais comprometidas com a otimização da contabilidade governamental do que com o atendimento de necessidades ou com o respeito às estratégias de sobrevivência das populações mais vulneráveis. As aproximações quantitativas visam a concentração de gastos em situações consideradas inaceitáveis, de acordo com formatos preestabelecidos que, por mais bem definidos que sejam, sempre partem de uma visão de mundo ou de parâmetros de prosperidade e desenvolvimento definidos em realidades diferentes daquelas tomadas como alvo. Para Sen (1992 apud LAVINAS, 2003), um patamar de renda pode revelar-se inadequado não porque se situa abaixo de uma linha de pobreza determinada por parâmetros exógenos, mas porque está abaixo do que é adequado para mobilizar um conjunto específico de habilidades (capabilities) compatíveis com as necessidades de uma determinada pessoa.

Dois parâmetros muito usados, definidos pela quantidade de dinheiro disponível para a obtenção dos bens necessários para a reprodução de um indivíduo em termos econômicos, são a linha de indigência e a linha da pobreza. A primeira é definida pela quantidade de dinheiro necessária para o acesso à alimentação; a segunda refere-se à quantidade de dinheiro necessária para agregar à alimentação despesas com vestuário, transporte e moradia. Essas linhas, baseadas apenas na renda, comprometem a mensuração de outro indicador, o 
crescimento (ou a diminuição da pobreza), auferido a partir de relações entre o número de pobres (ou de famílias pobres) e o número de habitantes (ou de famílias). O crescimento é um indicador muito utilizado, porém é limitado por não incorporar informações referentes à distribuição da renda ou ao acesso à renda não monetária, muito freqüente em áreas rurais de países em desenvolvimento (GOLDSCHMIDT-CLERMONT, 1992).

Outra limitação dos indicadores quantitativos de pobreza é seu caráter estático: são apresentados como uma fotografia da população naquele momento. Ao levar em conta exclusivamente a renda monetária, os indicadores superestimam a pobreza nos países menos avançados e semi-industrializados, onde indivíduos satisfazem suas necessidades nas cidades graças a estratégias não monetárias, como redes de solidariedade e trabalho voluntário. Ora, o fator solidariedade praticado no seio da família não é considerado pelos indicadores quantitativos de pobreza, desprezando-se a importância que a ajuda mútua no âmbito familiar teria nesse contexto para a superação da pobreza.

Por outro lado, esses indicadores não estabelecem diferença entre o modo de vida rural e o modo de vida urbano. Colocam todos os pobres no mesmo nível, o que não permite a estratificação das circunstâncias dos pobres ou a identificação de seu grau de vulnerabilidade. Esse tipo de indicador enfoca prioritariamente as situações em que o Estado deveria intervir para reduzir o impacto do empobrecimento, mas não orienta políticas que levem à superação da pobreza a longo prazo. De acordo com Cardoso (2002), o conceito de vulnerabilidade, emprestado de outros campos do conhecimento, traduz-se, nos estudos urbanos, por "insegurança e sensibilidade no bem-estar de indivíduos, famílias e comunidades diante de um meio ambiente em transformação, e implícito nisto sua capacidade de oferecer respostas e de resistir a riscos enfrentados em cada transformação negativa" (MOSER, 1998, p. 3). As transformações ou mudanças podem ser ecológicas, econômicas, sociais e políticas e muitas vezes contribuem para aumentar o risco e a incerteza e para o declínio do auto-respeito.

Dentro do domicílio, o conceito de vulnerabilidade pode estar também ligado à gestão dos recursos, de acordo com a idade, o sexo, as condições físicas, etc. Cardoso (2002) afirma que isso também permite um melhor entendimento de estratégias de subsistência em uma moradia, reconhecendo os pobres como agentes ativos que respondem o melhor que podem às circunstâncias em que se encontram. Assim a idéia de vulnerabilidade poderia captar a dinâmica de pessoas movendo-se para dentro e para fora da pobreza. Mesmo que nem todas as pessoas 
vulneráveis sejam pobres e que nem todos os pobres sejam sempre os mais vulneráveis, a aplicação do conceito de vulnerabilidade pode permitir uma melhor diferenciação entre populações de baixa renda (MOSER, 1998, p. 5).

As divergências metodológicas têm sido evidenciadas pelos desequilíbrios econômicos causados pela aplicação de soluções (receitas de reajuste econômico), propostas por órgãos internacionais, em países periféricos, nos quais é comum se observar o aumento do empobrecimento e a ampliação das desigualdades na distribuição de renda. Esses desequilíbrios econômicos são considerados necessários em um primeiro momento, devido à necessidade de redução de investimentos em ações de caráter social, mas, após alguns anos, constata-se que a relação entre crescimento e distribuição de renda é direta e nem sempre é acompanhada por uma diminuição da pobreza (SALAMA; VALIER, 1997).

Ao analisar dados do Índice de Desenvolvimento Humano fornecidos pelo PNUD (1996), Demo (1996) enfatiza que os índices, quando melhoram, tendem a melhorar para todos, tanto para os ricos quantos para os pobres (pobreza absoluta), entretanto para os ricos melhoram em uma proporção maior e num prazo de tempo menor (pobreza relativa). Esse tempo maior para a melhoria da qualidade de vida dos pobres traduz-se espacialmente na consolidação das áreas por eles habitadas na cidade ou das cidades formadas espontaneamente em regiões de fronteira econômica (como a região da Transamazônica). As áreas ocupadas pela população pobre no país são tradicionalmente vinculadas a uma condição periférica ou inadequada (loteamentos clandestinos, ocupações de áreas sujeitas a alagamentos ou desmoronamento, faixas de domínio de redes de alta tensão, conjuntos habitacionais isolados) devido à dificuldade de acesso à terra urbana mercadoria tanto mais cara, quando melhor a infra-estrutura. As populações pobres vivem um tempo de espera, necessário para a integração gradual daquelas áreas à cidade, quando são amalgamadas em bairros populares. Da mesma forma, na Amazônia, cidades novas, criadas a partir da emancipação de novos municípios, sustentados por uma economia voltada para a exploração mineral, de madeira e agropecuária, são constituídas segundo princípios semelhantes: quanto melhor for a localização dentro da rede urbana já existente, mais provável será o acesso a investimentos em infra-estrutura e a serviços.

Durante o processo de consolidação, as casas são melhoradas lentamente, e a pressão da comunidade sobre as autoridades e os políticos locais resulta na provisão de infra-estrutura física e, por conseguinte, 
Ana Cláudia Duarte Carddso / Marcília Regina Gama Negrão

de moradia - o que estaria acima das possibilidades de acesso dos habitantes em termos estritamente econômicos. Para alcançar esse estágio, a população convive anos com problemas de saneamento (relacionados à precariedade de acesso à água, às instalações sanitárias, à coleta de lixo, ao controle de vetores de doenças, ao lançamento de dejetos e esgoto), motivada pelos benefícios da localização, que lhe permite um acesso mais rápido e barato aos equipamentos públicos e às oportunidades de geração de renda oferecidos pela cidade. Em geral, tais áreas são beneficiadas por ações de maior envergadura quando deixam de ser consideradas periféricas em razão do processo contínuo de crescimento da cidade ou quando estão vinculadas a um eixo rodoviário importante. É preciso que a cidade cresça e enriqueça para que as áreas inicialmente mais precárias recebam melhorias e tornem-se habitáveis, ou é preciso que a região se torne economicamente mais dinâmica para que a cidade assuma novas funções (CARDOSO, 2002).

De acordo com as estratégias citadas, as condições de vida do indivíduo são gradativamente melhoradas (reduzindo-se o processo de empobrecimento) ainda que suas condições sociais de reprodução permaneçam as mesmas (ou que o indivíduo se mantenha na condição de pobre em termos econômicos). Tal diferenciação torna-se difícil em contextos fortemente influenciados por relações de solidariedade, autoemprego e autoconsumo, observadas nos assentamentos informais ou periféricos e em pequenas cidades sob forte influência rural.

\section{AS CAUSAS ESTRUTURAIS DA POBREZA DOS PAÍSES EM DESENVOLVIMENTO E O CASO DO BRASIL}

Na América Latina e na África, as desigualdades distributivas, tanto econômicas quanto sociais - e com elas toda a extensão da pobreza -, têm raízes profundas em traços culturais, na história e nos diversos padrões de inserção da economia na economia mundial. Diferente da pobreza produzida apenas pelas adversidades do mercado, a pobreza nesses continentes tornou-se estrutural. Para Koga (2003), o Brasil possui experiências históricas marcadas por um sistema autoritário. Dentre essas experiências, é possível destacar o sistema de escravidão, o patrimonialismo e a hierarquização nas relações sociais, definidas como um sistema descendente (que vem de cima para baixo).

Salama e Valier (1997) identificaram as principais diferenças entre os países da América Latina, particularmente Argentina, Chile, Brasil e México. Segundo esses autores, na Argentina e no Chile, a população indígena, pouco densa, foi erradicada; no interior da Argentina a 
distribuição de terras ocorreu de acordo com a quantidade de índios residentes. A mão-de-obra escrava foi pequena, e uma parte substancial da população era originária da Itália, de Portugal e da Espanha. Os padrões culturais eram os europeus, o que explica a importância das idéias anarcossindicalistas, até a década de 30, no movimento operário brasileiro ou argentino e a referência aos direitos do homem. Já nos países onde a colonização de povoamento não substituiu a população local, esta última foi submetida a uma exploração feroz, a ponto de se poder falar em genocídio de índios. Quando a quantidade de índios era insuficiente, essa carência era resolvida com a importação de mão-deobra escrava da África, o que permitiu a implantação de uma economia de exportação. Tais fatores foram preponderantes na formação da pobreza estrutural no Brasil, como se depreende da obra de Márcia Sprandel (2004). Infelizmente o processo de colonização da Amazônia também ocorreu de acordo com um segundo paradigma, não mais baseado na mão-de-obra escrava, mas fortemente dependente de uma intensa exploração do trabalho de grupos pouco qualificados, tanto nativos quanto migrantes, atraídos pelas frentes de trabalho e pela promessa de terras nos assentamentos rurais feita por grupos externos, economicamente privilegiados (como mineradoras, estatais do setor elétrico, madeireiras etc.), que perpetuaram as relações de dominação já existentes na região.

Para discutir as causas estruturais da pobreza no Brasil, Sprandel (2004) faz uma análise da representação da pobreza nas obras de autores clássicos do pensamento social brasileiro. Tais autores reconhecem a existência da pobreza no país, desde o "descobrimento", entretanto a abordagem da pobreza como problema nacional é mais recente. Em breve revisão bibliográfica, é possível constatar como se estruturou a pobreza no país. Roberto da Matta (1995 apud SPRANDEL 2004) apresenta uma concepção medieval da pobreza. Na Idade Média, quando predominavam os valores da Igreja Católica, a pobreza era tida como qualidade e condição de uma pessoa de qualquer status que estivesse sendo vítima de privações. A pobreza tinha valor social e despertava solidariedade e compaixão, além de admiração (tanto do pobre, quanto do rico que vivia com modéstia). Essa concepção de pobreza seria um processo compensatório da classificação social, segundo a qual pessoas ricas poderiam ser consideradas pobres em virtudes, e as pobres poderiam ser admiradas pela sua riqueza espiritual. Roberto da Matta enfatiza que somente a partir do século XIV, principalmente após a reforma protestante, a ordem social torna-se individualista e voltada para o mercado. A figura do pobre, até então vinculada à representação 
cristã, passa a ter uma outra leitura: o pobre passa a ser uma ameaça, e a pobreza passa a ser associada ao desemprego, à vagabundagem, à preguiça e ao crime.

A moralidade da Idade Média (cristã) foi substituída pela lógica do Estado, segundo a qual o Estado, e não o rico, passa a ser responsável pelo sobrevivência e pelo controle da população pobre, o que, de acordo com os estudos de Matta e Poovey (1998 apud SPRANDEL, 2004), acelerou o crescimento da pobreza. Até o final da Segunda Guerra, o debate sobre a pobreza centrava-se em questões raciais, vários pensadores afirmavam que o Brasil era um país sem nação. A pobreza foi considerada ora como resultado da mestiçagem, ora como resultado da escravidão. Para os moradores do interior do Brasil, caracterizados pela apatia, pela tristeza e pela doença, a pobreza seria mais um adjetivo.

Os abolicionistas, como José Bonifácio, afirmavam que jamais seríamos livres enquanto persistisse a escravidão. Mas alguns senhores tinham a coragem de alegar que, se os escravos parassem de trabalhar, faltariam alimentos para o consumo da população. Outros intelectuais, como Joaquim Nabuco, condenavam a escravidão e acreditavam que existia uma relação entre pobreza e escravidão. Segundo eles, o regime escravo, ao aumentar a dependência dos homens pobres e livres em relação a uma elite escravocrata e aristocrática, foi responsável pela ruína econômica do país e de seu povo.

Em sua obra, Sprandel (2004) mostra que Joaquim Nabuco era totalmente contra o latifúndio. Para ele, a pobreza dos negros era decorrente da dependência dos grandes proprietários de terras. Além de não terem casa para morar e terra para cultivar, os negros enfrentavam problemas alimentares. Para Joaquim Nabuco existiam três classes: os donos de escravos, os escravos e os miseráveis. Quando foram libertados, os escravos não possuíam emprego, moradia, etc.

De acordo com Prado (1942 apud SPRANDEL, 2004), o problema estava não na cor, mas no nível de desenvolvimento moral e intelectual das raças escravizadas. Essas raças, incluídas na sociedade brasileira durante o período colonial, eram orientadas por um outro sistema de valores, formando um "corpo estranho" e incômodo. O processo de absorção desse "corpo estranho" prolonga-se até os nossos dias e está longe de terminar. A rejeição das elites brasileiras aos processos de miscigenação não está ligada apenas à eliminação étnica, aspiração dos racistas brasileiros, que ainda se faz sem maiores obstáculos. O aspecto estético não é o aspecto mais grave do problema, a mistura de raças não tem para o país importância alguma e de certa forma pode até ser considerada vantajosa. O que pesou muito mais na formação da nação 
brasileira foi o baixo nível intelectual das massas escravizadas, que constituiriam a maioria da população do país (PRADO, 1942 apud SPRANDEL, 2004).

Após a Segunda Guerra, o problema da diferença racial dá lugar à questão da diferença de classes sociais. Depois da revolução da década de 30, houve uma aceleração das mudanças sociais e políticas. A partir dessa década, "pobre" deixa de ser apenas um adjetivo. A pobreza é associada à falta de oportunidade, à fome. Os autores passam a considerar a pobreza do homem do campo. Josué de Castro (1957 apud SPRANDEL, 2004), médico, considerado um visionário, em sua obra $O$ livro negro da fome, publicada em 1957, sustentava que o subdesenvolvimento do Brasil estava diretamente ligado à fome, que disseminava várias epidemias que levavam a população à pobreza. Josué de Castro ficou conhecido por sua luta implacável contra as desigualdades econômicas e a miséria dos povos que sofreram com a exploração colonial do mundo capitalista, denunciando a fome como um dos males sociais do subdesenvolvimento e do colonialismo.

Josué de Castro analisou as qualidades nutritivas da alimentação de pessoas de diferentes regiões do Brasil e do mundo, procurando identificar as causas fundamentais dessa alimentação. Chegou à conclusão de que a alimentação depende mais de fatores socioculturais do que geográficos. Criticou a inserção do Brasil na economia mundial e defendeu a reforma agrária como solução para se acabar com a fome no Brasil.

Em trabalho de campo, Antônio Cândido (1954 apud SPRANDEL 2004) procurou identificar um aspecto da vida social (a obtenção das formas de subsistência) das populações rurais que poderia constituir não apenas um tema sociológico, mas também "um problema social". Chamaram a atenção de Cândido o tipo de alimentação, as redes de solidariedade, a precariedade de direitos em relação à terra e a agregação do indivíduo à cidade como operário. Cândido concluiu que a solução para o problema rural seria a reforma agrária, como forma de abolir a fome e a anomia no meio rural.

Vitor Nunes Leal (1948) destacou a figura do coronel. Para ele, a base do coronelismo está na estrutura agrária que mantém os trabalhadores da roça em lamentável situação de incultura e abandono. Infelizmente, historicamente as mudanças políticas ocorridas no Brasil (República Velha, Estado Novo, Regime Militar) até a Constituição de 1988 mantiveram a estrutura de poder baseada na figura do coronel como líder local, especialmente nas áreas de acesso mais remoto, onde a falta de informação e a impunidade favoreciam a arbitrariedade, 
manifesta, por exemplo, no abuso do poder econômico, no controle de votos, na intimidação política e física, que marcaram profundamente as populações rurais e ainda constituem um grande obstáculo para a construção participativa de políticas comprometidas com a justiça social e a eqüidade. A partir da década de 60, questões como clima, raça, doença e fome deixaram de ser assunto dos debates nacionais. Durante a ditadura militar, graças ao aprofundamento das especializações universitárias, foram priorizados os estudos de classes e estruturas sociais, nos quais a pobreza e a desigualdade social eram elementos centrais.

A partir da promulgação da Constituição de 88, a pobreza tornase tema de reflexão política, mas inúmeros aspectos da trajetória brasileira mantêm-se vivos na Amazônia. Assim, assentamentos rurais promovidos pela reforma agrária tão esperada são substituídos por latifúndios, as condições de educação e capacitação profissional ainda são insuficientes para manter a população no campo e garantir seu acesso à vida urbana digna. Por outro lado, as políticas de desenvolvimento econômico implementadas na Amazônia não levaram em conta o impacto que causaram sobre as cidades (como processos de periferização, formação de assentamentos espontâneos e agravamento das assimetrias na rede urbana regional). De fato, tais políticas aprofundaram desigualdades socioespaciais, na medida em que permitiram a criação de espaços privilegiados para as elites e deixaram para os segmentos mais pobres, e menos capacitados, a tarefa de resolver por si mesmos as questões de habitação e de acesso a serviços e equipamentos urbanos.

Em sua análise das manifestações da pobreza no espaço urbano de Belém, Cardoso (2002) afirma que a pobreza é um problema multidimensional, que só pode ser enfrentado em uma abordagem participativa. Cardoso alinha-se assim com as interpretações que associam a pobreza à precariedade de direitos, à ausência de condições materiais para a sobrevivência e à desarticulação de valores nos segmentos sociais. A autora utiliza uma definição de pobreza construída com base na filosofia, na história e na ciência política, segundo a qual ser pobre é não ter perspectiva de vida ou estar privado de acesso a direitos básicos, como educação, assistência de saúde, trabalho remunerado, moradia e ambiente seguro, e estar separado de seu contexto social. O conceito de perspectiva de vida baseia-se em três dimensões: a disponibilidade de meios legais de acesso (direitos, meios financeiros), a disponibilidade de provisões (bens materiais, concretos, tomados como alternativas de escolhas) e as ligaduras, ou conexões, 
baseadas em valores, motivações que levam indivíduos a fazer opções entre as provisões disponíveis e considerando os meios legais de acesso de que dispõem. Em países desenvolvidos, tende-se a privilegiar a ampliação dos meios legais de acesso (garantias individuais e sociais), ao passo em que em países pobres as lutas estão concentradas na ampliação de provisões (habitação, por exemplo, em sentido amplo), ainda que para tanto sejam feitos sacrifícios e renúncias que só se justificam a longo prazo (morar sobre o alagado, enfrentar doenças, construir aterros e casas gradativamente).

No Brasil particularmente, a cidade representa um espaço de oportunidades, onde é possível ter acesso a facilidades e a equipamentos não disponíveis no meio rural ou em pequenas aglomerações. Também na cidade existe uma diversidade de valores e comportamentos que muitas vezes podem encarecer a sobrevivência (a reprodução de gostos elitistas reduz os recursos destinados à alimentação) ou ampliar a exposição a riscos ambientais e sociais (em áreas destituídas de infraestrutura física e social). Apesar de tudo, as cidades continuam sendo atrativas por garantirem mais facilmente certos direitos, dada a maior disseminação das informações e o maior potencial de mobilização. Nas cidades, graças a maiores investimentos em infra-estrutura, o aprovisionamento é mais rápido; nas cidades, é possível encontrar um grupo com valores sociais, religiosos, políticos, intelectuais, etc. semelhantes e assim fazer parte de uma rede social de apoio quando se está exposto à vulnerabilidade.

Em sua pesquisa empírica, Cardoso (2002) observou que os habitantes conseguem manter-se em áreas em processo de consolidação por aspirarem à melhoria e por aí encontrarem os meios para se apropriar dos benefícios que dela decorrem, diversificando as formas de geração de renda e assumindo valores voltados para o fortalecimento da comunidade e do meio em que vivem.

Ainda que baseada em um paradigma filosófico liberal, que admite a capacidade diferenciada de reação dos indivíduos em contextos desfavoráveis, essa análise das cidades procura explicitar estratégias aplicadas em contextos de insuficiência de políticas públicas, como o das regiões periféricas brasileiras. Para enfrentar o problema da pobreza em uma perspectiva de baixo para cima (com base nas necessidades dos futuros beneficiários) e assim recuperar a defasagem no atendimento ao cidadão historicamente desassistido, é preciso articular as políticas públicas - nas áreas de educação, saúde, habitação, infra-estrutura, desenvolvimento econômico, seguridade e assistência social, etc. A localização e o ritmo dos investimentos realizados nessas áreas podem 
Ana Cláudia Duarte Carddso / Marcília Regina Gama Negrão

ser compatibilizados com as necessidades e estratégias da população mais pobre que vive em aglomerados e em cidades, agilizando processos em curso, mas muito lentos.

\section{A POLÍTICA LIBERAL DE COMBATE À POBREZA}

As transformações ocorridas no âmbito mundial, que culminaram com a ascensão da política liberal, agravaram as dificuldades internas decorrentes da desarticulação das políticas setoriais aplicadas na Amazônia e da divergência de interesses entre os sujeitos envolvidos na urbanização da região. O liberalismo econômico impôs-se a partir da crise do sistema capitalista deflagrada pela crise do petróleo em 1973, quando, de acordo com Souza (2004), os neoliberais clamaram por um Estado mínimo e por maior confiança em um mercado livre. Essa política ganhou impulso decisivo no final da década de $70 \mathrm{com}$ a subida ao poder de Margaret Thatcher na Inglaterra e de Ronald Reagan nos EUA, tendo alcançado os países subdesenvolvidos a partir de meados da década de 80 e início da década de 90, período em que o governo federal retrocedeu em suas ações, após ter desencadeado profundas transformações fundiárias, ambientais, sociais e econômicas na região amazônica.

Se no âmbito mundial, o combate à pobreza pelas vias liberais implicou um custo social muito alto, na Amazônia o problema não foi sequer reconhecido. Para recuperar o equilíbrio orçamentário, os governos, além de diminuírem seus gastos sociais, ausentam-se totalmente do mercado, instituindo o liberalismo econômico tanto interno como externo, comportando-se na melhor das hipóteses como reguladores e muitas vezes na prática como expectadores. Quando a estratégia econômica sobrepõe-se não só aos anseios, mas também aos direitos sociais da população - os cidadãos transformam se em consumidores -, a luta torna-se desigual, vencendo o interesse dos mais fortes. Prevalece, então, o espírito empresarial, que procura atrair investimentos da iniciativa privada com a oferta de vantagens e regalias, como isenções tributárias, terrenos e infra-estrutura subsidiados, isenção de impostos, etc.

O próprio relatório do Banco Mundial (1993) admitia a hipótese de que as políticas econômicas de estabilização poderiam provocar "efeitos negativos" sobre os mais pobres durante um certo período, o que exigiria a elaboração de políticas de estabilização a curto prazo. O Banco recomendava ainda que se "esperasse" e que não se recorresse a políticas macroeconômicas com fins sociais ou redistributivos, criticando as políticas assistenciais populistas. De acordo com o relatório 
do Banco Mundial (1993), o bom funcionamento do mercado freqüentemente gera com maior naturalidade uma maior justiça social. Considerando a fragilidade das instituições de países como o Brasil e o peso do passado marcado por privilégios de certas classes sociais, programas de ajuste baseados em medidas estritamente econômicas reduzem significativamente as chances de melhoria das condições de vida das camadas mais pobres da população. Medidas relacionadas ao tempo necessário para o ajuste e correções de rumo em caso de fracasso são do maior interesse para os segmentos mais vulneráveis aos cortes em investimentos sociais (SALAMA; VALIER, 1997).

Conclui-se que as estratégias de combate à pobreza pelas vias liberais não garantem segurança aos pobres. O grande erro da política neoliberal está em admitir que o crescimento econômico constitui a única forma para solucionar o problema da pobreza nos países subdesenvolvidos. As políticas sociais liberais - uma reação crítica ao Estado do Bem-Estar Social - foram sistematicamente propostas pelas organizações internacionais e implantadas em muitos países subdesenvolvidos a partir do final da década de 80.

Segundo Salama e Valier (1997), o Estado de Bem-Estar caracteriza-se pelo estabelecimento de um sistema de proteção social definido em função de direitos sociais universais, ou seja, de um sistema que oferece garantias sociais a todos. De acordo com esses autores, os resultados de uma pesquisa realizada por Mesa-Lago com dados de 1985 indicam que a presença legal do Estado de Bem-Estar é nitidamente mais forte na América Latina do que na maior parte dos demais países subdesenvolvidos. No Brasil, o sistema de proteção social consolida-se principalmente nas décadas de 30 e 40, durante os regimes políticos populistas, com o objetivo de evitar ameaças de revoluções sociais.

É nítida a distinção entre direito (em termos conceituais) e realidade no sistema de proteção social. No que se refere ao acesso ao direito básico à habitação, por exemplo, a exclusão do sistema de proteção social é resultado do aumento considerável do setor informal e da diferença entre os recursos destinados aos ricos e aos pobres, de tal modo que os programas promovidos pelo Governo Federal, ao fim e ao cabo, destinamse a atender àqueles que fazem parte do setor formal da cidade.

A queda dos salários e o aumento do desemprego provocam uma diminuição sensível dos recursos financeiros do sistema, e essa diminuição é agravada pelo aumento do número de aposentadorias. A fraude e os atrasos de pagamento das contribuições sociais também aumentam. A constatação da insuficiência e da incapacidade de resposta do Estado de Bem-Estar Social em relação aos pobres é claramente 
Ana Cláudia Duarte Carddso / Marcilia Regina Gama Negrão

manifesta na disputa por habitação, educação e assistência de saúde. A política habitacional, por exemplo, desenhada durante o regime militar, foi fruto do diálogo com representantes da indústria da construção civil. Foi, pois, resultado de um processo decisório unilateral, imposto àqueles que seriam seus supostos beneficiários e aos gestores municipais, beneficiando o setor privado.

Dentre as críticas feitas ao modelo adotado pelo Sistema Financeiro da Habitação, Maricato (1996, p. 45) ressalta o fato de tal política combinar o atendimento dos interesses dos empresários privados com interesses políticos clientelistas. Na verdade, essa política foi fundamental para a estruturação de um mercado de orientação capitalista, que se constituiu em mais um expediente de concentração de renda, uma vez que privilegiou a produção de habitação subsidiada para a classe média em detrimento dos setores de mais baixa renda.

Quanto à educação, em virtude da precarização dos serviços públicos, as camadas mais abastadas matriculam seus filhos em escolas particulares, enquanto o pobre estuda no sistema do governo, de menor qualidade. O resultado é conferido nas universidades públicas, que beneficiam em geral as camadas mais abastadas. Com relação ao sistema de saúde e previdenciário, é comum a camada de maior poder aquisitivo recorrer a hospitais particulares e a planos de previdência privada.

O sistema de proteção social não foi um instrumento eficaz de combate à pobreza no Brasil. Nem por isso deve ser considerado promotor da pobreza nos países subdesenvolvidos. De acordo com Salama e Valier (1997), isso significaria negar os efeitos da própria crise, em termos de informalização e precarização maciça dos assalariados, visto que, na crise, não só a exclusão e a diferenciação, presentes na proteção social, cresceram, como também os próprios benefícios tenderam a diminuir. A orientação liberal intensificou os problemas sociais nas cidades amazônicas em formação, ainda fortemente dependentes da atuação do Estado. Com efeito, essas cidades eram e ainda são tanto menos atraentes para o setor privado quanto menos populosas e mais distantes das áreas produtivas. Dadas as limitações de resposta das cidades situadas perto de seus projetos, as grandes companhias estatais e privadas decidiram construir espaços segregados e independentes para os funcionários mais qualificados, desobrigandose em relação aos demais segmentos atraídos pelas frentes de trabalho, principalmente após o início do pagamento de royalties às municipalidades. 
Consideraçōes sobre a pobreza no Brasil e suas manifestaçōes nas cidades da Amazônia

\section{AS POLÍTICAS SOCIAIS LIBERAIS}

Esperar a volta do crescimento por meio do liberalismo econômico não é o suficiente, até porque, segundo o Banco Mundial, levará muito tempo para que essas políticas beneficiem os mais pobres da sociedade. Além disso, é possível que a pobreza e as desigualdades sociais aumentem temporariamente. Daí a necessidade de políticas sociais complementares e de efeitos imediato, enquanto se esperam os efeitos positivos do crescimento promovido por reformas liberais. O Banco Mundial foi o principal inspirador dessas políticas sociais, qualificadas de liberais por Salama e Valier (1997), que foram sistematicamente difundidas em todos os países em desenvolvimento.

Tais políticas sociais apresentam três características básicas: a) tratamento diferenciado para os extremamente pobres; b) privatização de formas de assistência e transferência de responsabilidades social; c) descentralização de políticas e estímulo à participação popular (Quadro 1).

\begin{tabular}{|c|c|}
\hline $\begin{array}{l}\text { 1. Tratamento } \\
\text { diferenciado para os } \\
\text { extremamente pobres }\end{array}$ & $\begin{array}{l}\text { Distinguem-se os pobres dos extremamente pobres, visto que os mais } \\
\text { pobres sấo mais vulneráveis aos impactos dos ajustes neoliberais e nẫo } \\
\text { contarn com polticas específicas, devido à premissa de que o alivio da } \\
\text { pobreza é conseqüência natural do restabelecimento do crescimento. } \\
\text { Propốe-se a criaçấo de redes de segurança, em várias formas de } \\
\text { programas destinados a assegurar alimentaçấo, educaçấo, capacitaçấo } \\
\text { profissional, melhorias do habitat nos bairros pobres, etc. } \\
\text { As políticas sociais focalizadas seriam temporárias, praticadas enquanto } \\
\text { o crescimento se recupera. Entretanto, o Banco Mundial avalia que } \\
\text { alguns indivíduos mais pobres continuarấo vulneráveis, mesmo depois } \\
\text { que as políticas liberais tiverem êxito. Por isso, algumas redes de } \\
\text { solidariedade deverấo continuar existindo. } \\
\text { Os empréstimos do Banco Mundial para esse tipo de politica têm } \\
\text { aumentado cada vez mais, dessa forma o combate abrangente à } \\
\text { pobreza é substituído pelo combate no varejo, orientado apenas para os } \\
\text { excluidos do mercado. }\end{array}$ \\
\hline $\begin{array}{l}\text { 2. Privatizaçẫo de } \\
\text { formas de assistência } \\
\text { e transferência de } \\
\text { responsabilidades } \\
\text { sociais }\end{array}$ & $\begin{array}{l}\text { Recorre-se às ONG para identificar grupos e distribuir a ajuda. } \\
\text { Os mais abastados abandonam o setor público e recorrem ao setor } \\
\text { privado. Introduz-se uma segmentaçẫo: de um lado, bens públicos - } \\
\text { bens e serviços de primeira necessidade para os mais pobres, sem } \\
\text { capacidade de compra; de outro, bens privados - bens e serviços mais } \\
\text { sofisticados destinados àqueles com capacidade de compra. }\end{array}$ \\
\hline $\begin{array}{l}\text { 3. Descentralizaçẫo de } \\
\text { políticas e estímulo à } \\
\text { participaçẫo popular. }\end{array}$ & $\begin{array}{l}\text { Políticas sociais descentralizadas, cada Estado fazendo uma contençẫo } \\
\text { local da pobreza. Fantani (1993, p. 8-15) pergunta-se se ainda é } \\
\text { possivel se falar de política social "nacional". Essa evoluçấo está ligada, } \\
\text { de acordo com o autor, ao fato de a classe operária organizada, ator } \\
\text { nacional entraquecido, deixar um espaço cada vez maior para uma } \\
\text { miríade de atores locais, justificando a participaçấo popular. }\end{array}$ \\
\hline
\end{tabular}

Quadro 1: Políticas sociais recomendadas pelo Banco Mundial 
Ana Cláudia Duarte Carddso / Marcília Regina Gama Negrão

Além dessas características, os programas de ajuste prevêem o atendimento das reivindicações trabalhistas de operários urbanos, muito atingidos pelo aumento da pobreza. Esses programas também têm favorecido a atuação de organizações não-governamentais internacionais no apoio aos excluídos e na organização do setor informal, cujo crescimento poderia ser atribuído à excessiva regulamentação que, contraditoriamente, impediria esse setor de se organizar.

Ainda com relação ao acesso a benefícios, Salama e Valier (1997) citam o exemplo das muitas ocupações ilegais em Allahabad (na Índia), cujos moradores não conseguem comprar comida com preços subsidiados porque teriam de dispor de um documento que só é entregue aos que têm uma habitação legal. Segundo esses autores, o apoio ao setor informal recomendado pelas organizações internacionais restringe-se a uma fração mínima de atividades, essencialmente às dos microempresários. Por fim, ao valorizar o desenvolvimento do setor informal, o Estado legitima o não respeito à lei e é levado, segundo Lautier, a administrar "uma sociedade de caos, cujo único princípio regulador seria a ordem mafiosa" (LAUTIER, 1987, p. 117). Entretanto, a promoção do setor informal é apresentada como um complemento às políticas focalizadas de assistência, destinadas ao combate à pobreza extrema (Quadro 2).

\begin{tabular}{|c|c|}
\hline Resultados sociais & $\begin{array}{l}\text { Os pobres que hoje já nẫo sẫo beneficiados pelo sistema de proteção } \\
\text { social nẫo podem esperar ser beneficiados amanhẫ. As condiçốes dos } \\
\text { trabalhadores do setor formal que foram beneficiados continuam } \\
\text { deteriorando-se. Os pobres que nấo sẫo extremamente pobres nẫo são } \\
\text { assistidos pelos programas focalizados, embora também necessitem de } \\
\text { recursos essenciais. } \\
\text { As polticas oferecem poucos serviços, por contarem com fundos } \\
\text { restritos, que sotreram um fenômeno de erosẫo ao longo dos anos. A } \\
\text { insuficiência das receitas tributárias e fiscais explica em parte a } \\
\text { insuficiência dos recursos mobilizados. }\end{array}$ \\
\hline Resultados políticos & $\begin{array}{l}\text { Politicamente as políticas sociais focalizadas de assistência conseguiram } \\
\text { conter os movimentos sociais e representam uma prova de eficiência, } \\
\text { legitinando as determinaçốes do Banco Mundial. Se as politicas sociais } \\
\text { focalizadas forem interpretadas como instrumentos para o } \\
\text { estabelecimento de um "pacto social" com as camadas mais pobres, com } \\
\text { o intuito de limitar os conflitos sociais e de obter legitimidade nessas } \\
\text { camadas, pode-se dizer entẫo que essas politicas alcançaram êxito } \\
\text { parcial. }\end{array}$ \\
\hline
\end{tabular}

Quadro 2: Resultado das políticas sociais liberais

O Banco Mundial, assim como todos os que pregam essas políticas focalizadas de assistência, afirma que elas poderiam constituir uma 
alternativa ao clientelismo, que tem comprometido o combate à pobreza. No entanto, a realidade é diferente. Essas políticas, de fato, muito longe de serem um instrumento de combate ao clientelismo, apenas dissimularam essa prática sob outras formas. Os canais de distribuição dos subsídios, que garantem o apoio político e a mobilização eleitoral, certamente mudaram, concentrando-se num nível local e setorizado. Assim, o combate à pobreza, definido por ações focalizadas, passa a depender da barganha política com as autoridades públicas. Portanto, o futuro do clientelismo está garantido, graças a essas políticas focalizadas de assistência.

Entretanto, embora essas políticas focalizadas de assistência tenham demonstrado eficácia, os resultados sociais foram pouco significativos, ainda que suficientes para garantir momentaneamente a legitimidade governamental. Assim, considera-se que as políticas de combate à pobreza, embora tenham apresentado êxitos políticos relevantes, tiveram resultados sociais fracos, reforçando e aprofundando as desigualdades sociais que visavam combater. A esse respeito, observese que tais medidas têm caráter nacional e, ainda que alcancem regiões de fronteira como a Amazônia, estão longe de mitigar os efeitos sociais e ambientais dos processos iniciados por ação governamental. O acesso limitado aos benefícios incentiva a busca do favorecimento político e a atitude de "salve-se quem puder", que compromete o amadurecimento das formas de organização existentes (institucionais, administrativas, sociais, espaciais) (trabalho de campo, 2005).

\section{AÇÕES GOVERNAMENTAIS DE COMBATE À POBREZA REALIZADAS NO BRASIL (DE 1985 A 2003)}

Na década de 90, a pobreza tornou-se parte do cenário político. Mais recentemente, é possível identificar as ações destinadas a combatê-la, promovidas pelo Governo Federal: os planos de prioridades sociais da Nova República - o Programa de Combate à Fome e à Miséria e pela Vida e o Programa Comunidade Solidária. Em relação aos planos de prioridades sociais da Nova República, observa-se que a intervenção estatal na área de alimentação e nutrição foi uma das prioridades políticas nos dois primeiros anos da Nova República. Esses planos sofreram algumas alterações operacionais e constituíram um dos principais instrumentos de legitimidade do projeto de transição democrática. As principais categorias empregadas no discurso desses planos eram: democratização substantiva da sociedade, ampliação das bases do 
consenso social, eliminação das desigualdades e extensão dos direitos sociais fundamentais (VASCONCELOS, 2005).

O programa Comunidade Solidária foi uma estratégia iniciada em 1995, no governo do presidente Itamar Franco. O programa contava com a participação do sociólogo Herbert de Souza (Betinho) e tinha como base o entrosamento governamental e o movimento social, além de priorizar três princípios: a solidariedade, a parceria e a descentralização. O programa visava melhorar a eficácia dos gastos públicos e ganhar efetividade na eliminação da pobreza. A partir do final de 1995, o programa passou a apresentar resultados positivos, ainda que restritos ao âmbito institucional, por meio da adoção de um novo padrão de articulação entre União, estados e municípios.

Apesar dos resultados positivos, o programa mostrou-se insuficiente em relação àquilo a que se propunha. Foi emperrado pela demora dos processos decisórios nas três esferas do governo, assim como pela inadimplência de estados e municípios, o que dificultava a celebração de convênios e o repasse de recursos federais (DEMO, 1996). Por conseguinte, o programa teve um impacto baixo ou quase nulo sobre a população mais pobre.

Esses programas sofreram descontinuidades e interrupções, e alguns foram totalmente extintos. Em 1999, a partir de uma proposta da criação do fundo de combate e erradicação da pobreza, apresentada pelo senador Antônio Carlos Magalhães, formou-se a Comissão Mista de Combate à Pobreza, composta por parlamentares de diversos partidos políticos.

De acordo com Sprandel (2004), essa comissão deveria estudar as causas estruturais e conjunturais das desigualdades sociais e apresentar soluções legislativas para erradicar a pobreza e a marginalização e reduzir as desigualdades sociais e regionais. A Comissão esteve em vigor de agosto a dezembro de 1999. A proposta de Antônio Carlos Magalhães foi alvo de inúmeras críticas, principalmente dos partidos de esquerda, que julgavam que a criação de um fundo de amparo à pobreza não seria a solução e que o problema real estava na distribuição de renda. Alguns parlamentares, como o senador Roberto Saturnino, apesar das críticas ao sistema capitalista, reconhecia a necessidade de políticas compensatórias para os mais pobres.

Para Márcia Sprandel (2004), que acompanhou algumas reuniões no plenário sobre o projeto, o projeto não obteve grandes resultados em razão da "pobreza da política", que se deve à disputa pelo poder. Segundo a pesquisadora, os políticos utilizam o tempo nas rádios e na televisão para autopromover-se, em discursos inflamados e sem conteúdo, além 
de elaborarem leis que não respondem às necessidades do país, grande parte delas copiadas dos Estados Unidos ou da Europa, revelando uma visão extremamente clientelista da pobreza.

Demo (1996, p. 111) enfatiza que, na prática, o assistencialismo e o clientelismo contaminaram sempre o esforço nacional concentrado nas ações sociais voltadas para grupos pobres. Com a democratização da década de 80, até mesmo em reação a essa tradição, passaram a predominar, no plano das concepções, três eixos valorativos e de organização dos programas: o universalismo, e não a seletividade ou a focalização, a opção pelos serviços estatais gratuitos e a preferência por programas do tipo assistencial, mais que pelos do tipo "produtivo"; ou de capacitação de geração e renda. A maior facilidade de acesso a benefícios vinculados a programas compensatórios em cidades onde predomina a população pobre (em termos monetários) e a estagnação econômica tornaram jovens e adultos dependentes de crianças e idosos - beneficiários de programas de assistência e previdência social. Nessas áreas, a discussão da cidade como espaço produtivo e potencializador de oportunidades de capacitação e geração de renda foi deixada em segundo plano, diante da possibilidade de sobrevivência imediata com menor esforço, do recurso ao clientelismo e do fácil acesso aos prazeres urbanos (como festas, consumo de álcool e fumo) (trabalho de campo, 2005).

\section{CONSIDERAÇÕES FINAIS (OU CONTRIBUIÇÕES DO LIBERALISMO PARA A CONSTRUÇÃO DAS CIDADES BRASILEIRAS E AMAZÔNICAS)}

Enquanto nas décadas de 50 e 60, em âmbito mundial, intensificouse o crescimento do capitalismo, assim como a utilização do planejamento urbano convencional para dirigir e controlar o crescimento físico da cidade, na Amazônia, o planejamento regional, comprometido com o desenvolvimento econômico e a integração nacionais, prevalecia sobre qualquer reflexão sobre a cidade. A cidade era considerada ou interpretada como mero resultado de processos muito eficazmente implantados. Quando a grande recessão econômica ocorrida nas décadas de 70 e 80 atingiu as cidades de tradição industrial mundo afora, as cidades tornaram-se alvo das ações desregulamentadoras impostas pelo liberalismo econômico. Os teóricos do planejamento tomaram-nas como máquinas de fazer riqueza, e "o planejamento deixou de controlar o crescimento urbano e passou a encorajá-lo por todos os meios possíveis e imagináveis" (HALL ,1995, p. 407). 
A nova forma de planejamento urbanístico, definida por Souza (2004) como planejamento estratégico, passou a ajustar-se ao interesse do capital. Na Inglaterra, é possível destacar o caso da revitalização das Docklands, uma enorme área às margens do rio Tamisa, que abrigava enormes corporações públicas. As corporações foram remanejadas, e a área foi transformada em marina, espaço de lazer, com serviços e residências luxuosas. Segundo Hall (1995), as comunidades portuárias locais, tradicionalmente das classes trabalhadoras, perderam seu meio de vida.

Na Amazônia, o processo de urbanização não resultou da industrialização ocorrida nas cidades, mas de um processo de exploração de recursos naturais, independente das cidades existentes, reforçando desigualdades históricas existentes entre segmentos sociais privilegiados e oprimidos. As mudanças nas ações e nas políticas públicas do Governo Federal aumentaram a vulnerabilidade da população nativa, na medida em que prevaleceram paradigmas de colonização da terra rural e de urbanização importados de outras regiões, completamente diferentes daqueles adotados localmente. Contribuíram para isso a forte migração desencadeada pela grande quantidade de terra disponível, de baixo custo, as ambigüidades fundiárias, a baixa capacidade administrativa das instituições envolvidas, assim como a baixa escolaridade da população e sua forte dependência do extrativismo e da agricultura de subsistência.

A imposição do liberalismo agravou as desvantagens da população rural nativa, que se transferiu para as cidades em busca de benefícios sociais e serviços gratuitos de educação e saúde, tanto quanto de oportunidades de trabalho. Nessas circunstâncias, a condição material da habitação, e mesmo da cidade, importa menos que as possibilidades de acesso à cidadania que as cidades podem oferecer, ainda que a médio ou a longo prazo.

Paralelamente a isso tudo, assistimos ao aparecimento no Brasil, durante a década de 90, dos planos estratégicos, na esteira da descoberta do potencial econômico das cidades. O exemplo mais conhecido é o do Rio de Janeiro, que deveria vender uma imagem favorável do município. Era a operação city marketing, como definiu Souza (2004). O objetivo central desse plano foi atrair para o município a geração de negócios, com destaque para o turismo. Ao fim e ao cabo, o novo modelo urbanístico proposto voltou-se para o mercado e beneficiou apenas as classes de mais alta renda, no que diz respeito à moradia, à infra-estrutura, aos equipamentos e aos serviços. Comprovou-se mais uma vez que a urbanização realizada de acordo com as necessidades do mercado reforça 
desigualdades e a desestruturação da cidade, concentrando os benefícios em áreas restritas.

Apesar da defasagem histórica e da falta das provisões e da infraestrutura requeridas pelo último modelo, a influência dessa estratégia nas cidades da Amazônia já pode ser sentida na expectativa de mudança no espaço situado na frente das cidades, tanto nas de beira de rio, quanto nas de beira de rodovia. Em ambos os casos, são necessários projetos que transformem esse espaço em áreas de lazer e contemplação, com o intuito de criar uma identidade para essas cidades, atrair visitantes e assim contribuir para a redução da pobreza, mas também expressar os novos valores da elite dominante. Ecos da política liberal alcançam rapidamente as pequenas cidades, mas não há mudanças nas políticas sociais. Tanto na periferia das capitais e das cidades médias, quanto nas pequenas cidades da região amazônica, a população pobre ainda busca a segurança da posse, o controle da localização e do custo da habitação, evitando endividar-se e tentando reduzir os custos de transporte. A relação da habitação com a segurança alimentar, assegurada pela produção de hortas, pela criação de animais e pelo estabelecimento de redes de solidariedade (entre parentes e vizinhos), explica essa população sobrevive, apesar de suas limitações monetárias.

Nas cidades onde se justifiquem ações orientadas para o turismo, é preciso que não se atribua aos projetos de frente de cidade a capacidade de reduzir a pobreza, sob pena de aumentá-la, pelo comprometimento de atividades e de estratégias que efetivamente contribuem para a subsistência da população mais pobre, excluída da economia formal, que sobrevive da venda de produtos trazidos dos rios e da floresta nas feiras (nas cidades de beira de rio) e da venda de sua força de trabalho no setor de serviços (nas cidades de beira de estrada) (trabalho de campo, 2005).

Finalmente, consideramos que, em cidades onde predominam os pobres (em termos monetários) e onde se busca reduzir a pobreza, importa mais se o processo é conduzido de modo a incluir os historicamente excluídos, respeitando estratégias de subsistência que já provaram ser viáveis, do que a conclusão de mais uma obra ou uma grande intervenção. 


\section{REFERÊNCIAS}

BANCO MUNDIAL. Implementing the World Bank's strategy to reduce poverty, progress and change. Washington, 1993.

CARDOSO, Ana. The alternative space: informal settlements and life chances in Belém, Brazil. 2002. Tese (Doutorado em Arquitetura) - Oxford Brookes University, Oxford, 2002.

DEMO, Pedro. Combate à pobreza: desenvolvimento como oportunidade. Campinas, Autores Associados, 1996.

FANFANI, Emílio. L'état de l'État social en Argentine. Trabalho apresentado no Colóquio do Greidt, França, 1993. Mimeografado.

GOLDSCHIMIDT-CLERMONT, Luisella. Measuring households'nonmonetary production. In: EVANS, Paul; MAX-NEEF, Manfred (Ed.). Real-life economics: understanding wealth-creation. London: Routledge, p. 265282. 1992

GOUGH, Ian. Global capital, human needs and social policies. London: Palgrave, 2000. Selected Essays: 1994-99.

HALL, Peter. Cidades do amanhã. São Paulo: Perspectiva, 1995.

KOGA, Dirce. Medidas de cidades: entre território de vidas e territórios vividos. São Paulo, Cortez, 2003.

LAUTIER, Bruno. Fixation restreinte dans le salariat, secteur informel et politique d'emploi en Amérique Latine. Revue Tiers Monde, Paris, n. 110, p. 346-367, avr./juin 1987.

LAVINAS, Lena. Pobreza, desigualdade e exclusão: contextos atuais. In: SEMINÁRIO INTERNACIONAL DA URB-AL, 10., 2003. São Paulo. Anais... São Paulo: PMSP, 2003. Disponível em: <www.prefeitura.sp.gov.br>.

LEAL, Vitor. Conceituação e conseqüências do coronelismo: sinais de crise do sistema. Perspectivas. In: MENESES, D. (Org.). O Brasil no pensamento social brasileiro. Brasília: Senado Federal, p. 271-279. 1948.

MARICATO, Ermínia. Metrópole na periferia do capitalismo: ilegalidade, desigualdade e violência. São Paulo: HUCITEC, 1996.

MOSER, Caroline. The asset vulnerability framework: reassessing urban poverty reduction strategies. World Development, Oxford, v. 26, n. 1, p. 1-19, jan. 1998.

116 
PNUD; IPEA. Relatório sobre o desenvolvimento humano no Brasil. Rio de Janeiro: IPEA; Brasília: PNUD, 1996.

SALAMA, Pierre; VALIER, Jacques. Pobrezas e desigualdades no Terceiro Mundo. São Paulo: Nobel, 1997.

SOUZA, Marcelo. Mudar a cidade. Rio de Janeiro: Bertrand Brasil, 2004.

SPRANDEL, Márcia. A pobreza no paraíso tropical: interpretações e discursos sobre o Brasil. Rio de Janeiro: Relume Dumará, 2004.

TOWNSEND, Peter. The international analysis of poverty. Londres: Prentice-Hall, 1993.

VASCONCELOS, Francisco. Combate à fome no Brasil: uma análise histórica de Vargas a Lula. Florianópolis: UFSC, 2005.

\section{Outras fontes:}

Trabalhos de campo (levantamentos físicos, aplicação de questionários e entrevistas com a população, os movimentos sociais e a administração local) realizado nas cidades de Placas (2005), Medicilândia (2005), Pacajá (2005), Novo Repartimento (2005) e Igarapé-Miri (2005). 